\title{
Mechanical Properties Optimization of Cellulose Nanofiber/Graphene Oxide Nanocomposite Produced by Mixing Method
}

\author{
Aditia Warman ${ }^{1}$, Saharman Gea ${ }^{2}$, Darwin Yunus Nasution ${ }^{3}$, Ardiansyah Sembiring ${ }^{4}$, Yasir \\ Arafat Hutapea ${ }^{5}$, Nami Panindia ${ }^{6}$ \\ \{s.gea@usu.ac.id $\left.{ }^{2}\right\}$ \\ University of Sumatera Utara, Indonesia ${ }^{1,2,3,4,5,6}$
}

\begin{abstract}
This research implemented a green route to multifunctional nanocomposite materials composed by cellulose nanofiber (CNF) and graphene oxide (GO). Aqueous solutions with different ratio of GO (prepared with $\mathrm{LiCl} / \mathrm{DMAc} 8 \%\left({ }^{\mathrm{w}} / \mathrm{v}\right)$ ) were mixed with cellulose nanofiber by using magnetic stirrer at the temperature of $70{ }^{\circ} \mathrm{C}$ for 30 minutes. The mixture obtained was dried in room temperature for 24 hours. The nanocomposite were characterized with several analysis such as; Fourier Transform Infrared (FTIR), mechanical properties testing, Transmission Electron Microscope (TEM), and Scanning Electron Microscope (SEM) analysis. The characteristic of cellulose nanofiber functional groups was exhibited through FTIR spectra. The CNF/GO with $0.06 \mathrm{wt} \%$ indicated a higher mechanical properties compared to the CNF. Its tensile strength increased drastically from 26.36 MPa to 49.69 MPa while its young's modulus also showed an extreme increase from $1.379381 \mathrm{GPa}$ to $6.973478 \mathrm{GPa}$ respectively. Moreover, cellulose nanofiber diameter had been examined through TEM and its morphology was analyzed with SEM. Finally, it can be concluded that the celulose nanofiber mechanical properties can be optimized by graphene oxide through the mixing process.
\end{abstract}

Keywords: Cellulose Nanofiber, Graphene Oxide, Nanocomposites, Mechanical Properties, Mixing Method.

\section{Introduction}

Oil palm empty fruit bunches (OPEFB)is by-product of steam sterilization process of oil palm plantations (PKS)(Or, Putra and Selamat, 2017), which can be used as a source of cellulosic fibers., while cellulose nanofibers or cellulose nanofibrils (CNFs) are obtained from OPEFB (Ferrer et al., 2012), which has at least one dimension in nanometer range and low thermal expansion, high specific area, good mechanical, optical properties are had them(Feng et al., 2018), obtained from the steam explosive method. Steam explosive method in alkali medium followed by hydrochloric acid treatment and high shear homogenization is an effective method to be used in the separation of cellulose nanofiber from lignin and hemicellulose (Saelee et al., 2016),(Kaushik and Singh, 2011).

Thus, the development of nanocomposites based on CNF is widely used in various regions as reinforcement and CNF has the ability to absorb more energy than synthetic fibers (Kalia et al., 2011)and usually be applied for sensors, cosmetics and biomedicine (Feng et al., 
2018). One of the method in reinforcing CNF by reinforcement agents, such as graphene oxide (GO) (Wang, Wu and Huang, 2018).

Graphene oxide (GO) is a material where the electronegative oxygen atom is bound to the graphite structure(Lu, Ocola and Chen, 2009). GO can be generated by the Hummers method. The Hummers method is one of the methods used to oxidize strongly graphite using $\mathrm{K} 2 \mathrm{Cr} 2 \mathrm{O} 7$ or KMnO4(Sitko et al., 2013)-(Alam, Sharma and Kumar, 2017). The electrical, mechanical, and thermal properties of polymeric material could be improved by $\mathrm{GO}$ (Amaturrahim et al., 2018).

Improvement transitional behavior of mechanical and thermal properties of material composite using blending method with modify cellulose in solvent. Enhancing properties of cellulose can be greatly enhanced by inorganic fillers(Zhang et al., 2012). Nanocomposite materials based on renewable and natural polymer which was fabricated from fuctional graphene is importance. The comparing of filler and polymer matrix can lead to enhance functional properties and can be used potentially wide-ranging applications(Phiri et al., 2018).

In this studying, $\mathrm{GO}$ was fabricated from strong oxidation of graphite which was blended with $\mathrm{LiCl} / \mathrm{DMAc} 8 \%$ via ultrasonicator resulting $\mathrm{GO}$ activated of $\mathrm{LiCl} / \mathrm{DMAc}$. The purpose of this research is to make regenerated films from cellulose nanofiber/graphene oxide nanocomposites in the solvent $\mathrm{LiCl} / \mathrm{DMAc} 8 \%$ and evaluated its mechanical properties. Functional groups spectra, dimension of CNF, morphology and mechanical properties (tensile strength) were characterized in this work as well.

\section{Materials And Methods}

\subsection{Materials}

Oil palm empty fruit bunches (OPEFB) as raw material was collected from PTPN IV Adolina, Serdang Berdagai, Indonesia. Sodium hydroxide $(\mathrm{NaOH})$, sodium hypochloride $(\mathrm{NaOCl})$, hydrogen peroxide $(\mathrm{H} 2 \mathrm{O} 2)$ 30\%, hydrochloric acid $(\mathrm{HCl}) 37 \%$, aceton, lithium chloride $(\mathrm{LiCl}), \mathrm{N}, \mathrm{N}$ dimethyl acetamide (DMAc) were purchased from Sigma Aldrich Singapore. Graphene oxide was prepared via a modified Hummers Method through an acid oxidation towards the graphite.

\subsection{Isolation of $\alpha$-Cellulose from Oil Palm Empty Fruit Bunches (OPEFB)}

OPEFB was cutted into $3 \mathrm{~cm}$ length and washed with tap water to clean up the dirt. After being cleaned, it was soaked into water overnight and oven dried at $80^{\circ} \mathrm{C}$. About 75 gr of dried OPEFB treated with $1 \mathrm{~L}$ of $2 \% \mathrm{NaOH}$ and stirred for 4 hours at $50^{\circ} \mathrm{C}$ to remove the major part of the lignin and hemicellulose(Julie Chandra, George and Narayanankutty, 2016) . Next, they were prepared by steam explosion in autoclave and $\mathrm{NaOH} 2 \%$ at $130{ }^{\circ} \mathrm{C}$ and the pressure was $180 \mathrm{kPa}$ for 2 hours. Then, fibers were washed with distilled water until the neutral $\mathrm{pH}$ was reached(Saelee et al., 2016),(Salehudin et al., 2014). After that, bleaching process was conducted using sodium hypochloride solution with 6-14\% of concentration (Salehudin et al., 2014).

To separate $\alpha$-cellulose from $\beta$ and $\gamma$-cellulose, a dried bleached OPEFB was soaked into $17.5 \% \mathrm{NaOH}$ at $70{ }^{\circ} \mathrm{C}$ for 2 hours. This mixture was then filtered, washed with distilled water until its $\mathrm{pH}$ was neutral. The bleaching process was performed one more time with $10 \%$ 
$\mathrm{H}_{2} \mathrm{O}_{2}$ for 2 hours at $70{ }^{\circ} \mathrm{C}$ to remove the remaining lignin and hemicellulose. Finally, it was dried in an oven at $50^{\circ} \mathrm{C}$ and after that was kept in vacuum desicator (Kaushik and Singh, 2011)(Ohwoavworhua and Adelakun, 2005),(Sinaga et al., 2018).

\subsection{Treatment for Isolating Cellulose Nanofibers (CNFs)}

The $\alpha$-cellulose that had dried was hydrolized with $10 \%$ hydrochloric acid $(\mathrm{w} / \mathrm{v})$ via ultrasonication for 3 hours and washed with distilled water until its $\mathrm{pH}$ reached neutral. After that, it was homogenized with high shear homogenizer at $8000 \mathrm{rpm}$ for 4 hours and the resulted suspension was filtered and dried in an oven at $50{ }^{\circ} \mathrm{C}$ (Feng et al., 2018),(Julie Chandra, George and Narayanankutty, 2016),(Lee et al., 2009).

\subsection{Synthesis of Graphene Oxides from Commercial Graphite}

As much as $2 \mathrm{~g}$ of graphite were putted into a beaker glass. Then, an amount of $2 \mathrm{~g}$ of $\mathrm{NaNO}_{3}$ and $150 \mathrm{ml}$ of $\mathrm{H}_{2} \mathrm{SO}_{4}(\mathrm{c})$ were added while the mixtured was stirred for 2 hours in ice bath. Then, 10 grams of $\mathrm{KMnO}_{4}$ (s) was gradually added and stirred for 4 hours at $20{ }^{\circ} \mathrm{C}$. After that, it was transferred from ice bath and stirred for 20 hours at $35{ }^{\circ} \mathrm{C}$. Then, $200 \mathrm{~mL} 5 \% \mathrm{H}_{2} \mathrm{SO}_{4}$ and $10 \mathrm{~mL} 30 \% \mathrm{H}_{2} \mathrm{O}_{2}$ were added and stirred for 1 hour. The centrifugation was conducted at $7200 \mathrm{rpm}$ for 10 minutes until the supernatant and sediment were clearly separated. The sediment obtained was washed with warm distilled water until the $\mathrm{pH}$ approached 7 . Then, it was ultrasound at $5060 \mathrm{~Hz}$ for 5 hours. The centrifugation was conducted again at $7200 \mathrm{rpm}$ for 10 minutes to obtain sediment. Then, the precipitate was dried in an oven at a temperature of $105^{\circ} \mathrm{C}$ to obtain graphene oxide powder. Graphene oxide powder was characterized by XRD and FTIR(Song et al., 2014).

\subsection{Fabrication of CNF/GO Nanocomposites}

Firstly, cellulose nanofibers (CNFs) were activated while stirred using distilled water, acetone and DMAc each for 1 hour and filtered. The activated sample was put into $8 \% \mathrm{LiCl} / \mathrm{DMAc}$ $\left({ }^{\mathrm{w}} / \mathrm{v}\right)$ solution. The solution was heated at $70^{\circ} \mathrm{C}$ for $30 \mathrm{mins}$ until it formed the gel. Transparent solution was obtained after 24 hours. Colloid of graphene oxide (GO)in $8 \% \mathrm{LiCl} / \mathrm{DMAc}\left({ }^{\mathrm{w}} / \mathrm{v}\right)$ was prepared by adding $20 \mathrm{mg}$ GO into $40 \mathrm{ml} 8 \% \mathrm{LiCl} / \mathrm{DMAc}\left({ }^{\mathrm{w}} / \mathrm{v}\right)$ solution with mild ultrasound sonication for 24 hours. The CNF/GO composites were prepared by putting the obtained two solutions together according to mass ratios of CNF to GO: 100/0 (RC), 99,8/0,2 $(\mathrm{RC} 0,2), 99,6 / 0,4(\mathrm{RC} 0,4), 99,4 / 0,6(\mathrm{RC}), 6)$. The mixture solutions were stirred at $70^{\circ} \mathrm{C}$ for 30 minutes and then spread over a glass plate. The glass plate covered with the mixed solution was coagulated in the air and the film was detached in distilled water. The detached film was soaked in running water for overnight. The mixture film was finally dried and stored. The CNF/GO nanocomposite films were characterized by mechanical properties testing and scanning electron microscope (SEM) analysis(Zhang et al., 2012)

\subsection{Characterization}

The CNF/GO nanocomposites characterized by Fourier transform infrared (FTIR) spectroscopy of cellulose nanofiber (CNF) were recorded with Shimadzu IR Prestige-21 spectrometer using $\mathrm{KBr}$ pellet. All FTIR spectra were recorded in the wave number with range of 4000-500 $\mathrm{cm}^{-1}$. The dimension of CNF were observed under high resolution TEM using a 
JEM-1400 electron microscope with an accelerating of $100 \mathrm{~V}$. Mechanical properties of CNF/GO nanocomposites were measured by Instron 5567 testing machine at $1 \mathrm{~mm} / \mathrm{min}$ of speed at room temperature. The rectangular specimen $(50 \mathrm{~mm} \times 15 \mathrm{~mm} \times 0.4 \mathrm{~mm})$. The morphology of $\mathrm{CNF} / \mathrm{GO}$ nanocomposites were exhibited by scanning electron microscope (SEM) HITACHI S3400N Japan and operated at $10.0 \mathrm{kV}$ ). Samples were recorded at a magnification between 200 to 1000x. All measurements were performed for at least three samples and the average value was recorded.

\section{Result And Discussion}

\subsection{FTIR Analysis}

The FTIR spectrum of cellulose nanofiber is shown in Figure 1. The peak in area of $3387 \mathrm{~cm}^{-1}$ shows - $\mathrm{OH}$ stretching band, that is, due to vibrations hydrogen bonded hydroxyl group in the cellulose structure. The peak at $2916 \mathrm{~cm}^{-1}$ corresponds to the aliphatic saturated $\mathrm{C}-\mathrm{H}$ stretching vibration of cellulose and hemicellulose(Kaushik and Singh, 2011). The sharp peak at $1627 \mathrm{~cm}^{-1}$ shows thedeformation vibration of the $\mathrm{OH}$ band on the intercalated water molecule. The peak at $1427 \mathrm{~cm}^{-1}$ indicates the curve of the $\mathrm{HCH}$ and $\mathrm{O}-\mathrm{CH}$ bonds. The peaks at $1165,1111,1056 \mathrm{~cm}^{-1}$ show the asymmetric bridge streching of $\mathrm{C}_{1}-\mathrm{O}-\mathrm{C}_{4}, \mathrm{C}_{2}-\mathrm{O}_{2} \mathrm{H}$, and $\mathrm{C}_{1}$ $\mathrm{O}-\mathrm{C}_{5}$ pyranose ring skeletal streching and $\mathrm{C}_{6} \mathrm{H}_{2}-\mathrm{O}_{6} \mathrm{H}$ respectively(Amaturrahim et al., 2018).

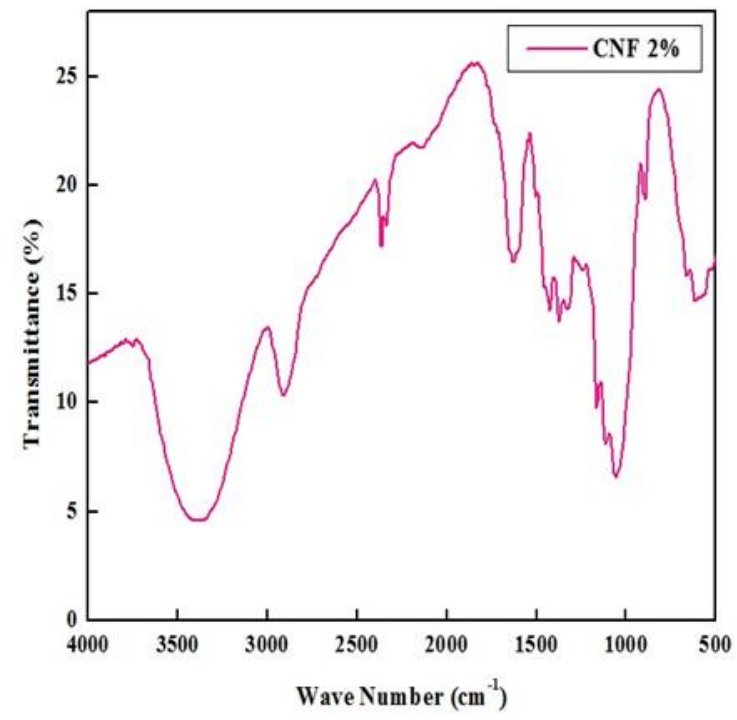

Figure.1.FTIR spectrum of $2 \%$ cellulose nanofiber (CNF). 


\subsection{Mechanical Properties of CNF Nanocomposites}

To evaluate the reinforcing effect of graphene oxide in $\mathrm{CNF} / \mathrm{GO}$ nanocomposites, tensile strength test of pure cellulose nanofiber and three $\mathrm{CNF} / \mathrm{BC}$ films with a graphene oxide content of 0.02, 0.04, $0.06 \mathrm{wt} \%$, respectively was conducted. The representative stress-strain curves are shown in Figure 2 and mechanical properties of the film are summarized in Tabel 1. Tensile strength of cellulose nanofiber from mixing method was drastically increased comparing without graphene oxide.

Mechanical properties of the CNF/GO nanocomposite films are not depend on fibril modulus but also interaction between cellulose nanofiber and graphene oxide. Mechanical properties of CNF/GO nanocomposites have improved with the increasing of graphene oxide loadings. Incorporation of $0.06 \mathrm{wt} \%$, graphene oxide significantly improved the mechanical properties of cellulose nanofiber (Amaturrahim et al., 2018). For example, the Young modulus of nanocomposite film with $0.06 \mathrm{wt} \%$ of graphene oxide was $6.97 \mathrm{Gpa}$,corresponding to an increase of $505.55 \%$ compared to $1.37 \mathrm{GPa}$ of pure cellulose nanofiber film. The tensile strength was increased to $49.69 \mathrm{MPa}$, corresponding to an increase of $188.5 \%$ compared to 26.36 MPa of pure cellulose nanofiber film. The elongation at break changed much with addition graphene oxide(Zhang et al., 2012), indicating that dispersion of graphene oxide nanosheet on the molecular scale in cellulose nanofiber matrix and also the interaction between cellulose nanofiber and graphene oxide made a great contribution to the mechanical enhancement. The oxygen containing groups on graphene oxide can interact with $\mathrm{OH}$ on cellulose nanofiber through hydrogen bonding both intra and intermoleculary. The elongation at break decreased from $20.92 \%$ (cellulose nanofiber) to 3\% (cellulose nanofiber/0.06) due to the brittle nature of graphene oxide nanosheet(Amaturrahim et al., 2018).

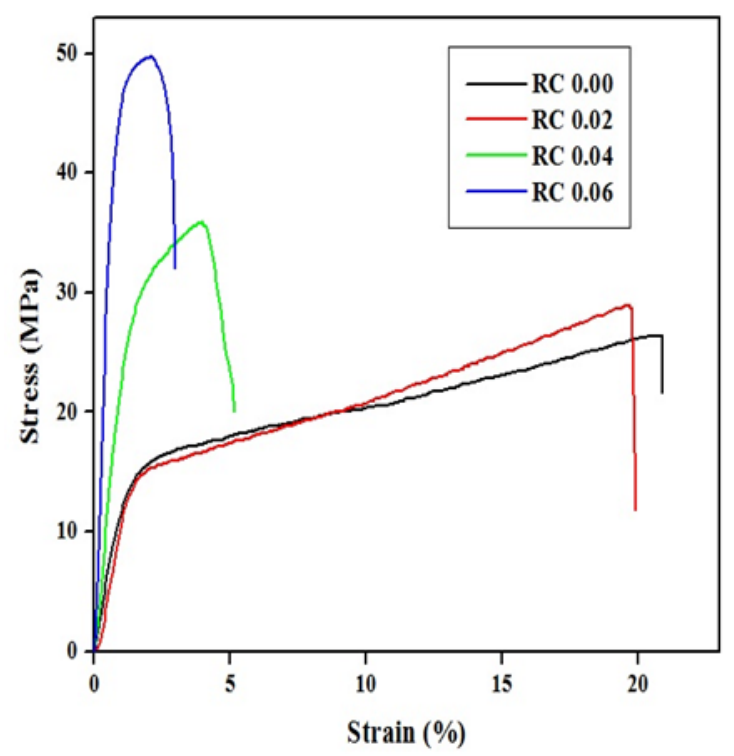

Figure 2. Stress-strain of curves of cellulose nanofiber/graphene oxide (CNF/GO) nanocomposite films with graphene oxide content of $0.00,0.02,0.04$ and $0.06\left({ }^{\mathrm{w}} / \mathrm{v}\right) \%$ 
Table 1.Mechanical properties of cellulose nanofiber/graphene oxide (CNF/GO) nanocomposite films with different graphene oxide contents.

\begin{tabular}{llll}
\hline Sample & $\begin{array}{l}\text { Young Modulus } \\
(\mathrm{GPa})\end{array}$ & $\begin{array}{l}\text { Tensile Strength } \\
(\mathrm{MPa})\end{array}$ & $\begin{array}{l}\text { Elongation at break } \\
(\%)\end{array}$ \\
\hline RC 0.00 wt\% & 1.379381 & 26.36 & 20.92308 \\
RC 0.02 wt\% & 1.2911 & 28.89 & 19.88676 \\
RC 0.04 wt\% & 2.747574 & 35.86 & 5.19988 \\
RC 0.06 wt\% & 6.973478 & 49.69 & 3.00000 \\
\hline
\end{tabular}

\subsection{Morphology of CNF/GO Nanocomposites}

Tranmission electron microscope (TEM) was used to investigate the diameter distribution diameter of cellulose nanofiber. Figure 3 shows TEM image of distribution of nano-fiber diameter of cellulose nanofiber. The average fiber diameters is found in the range $20-60 \mathrm{~nm}$. A tendency of agglomeration could also be observed from TEM. The particle was found least diameter at $25.612 \mathrm{~nm}$ and the biggest diameter at $58.82 \mathrm{~nm}$ (Kaushik and Singh, 2011).

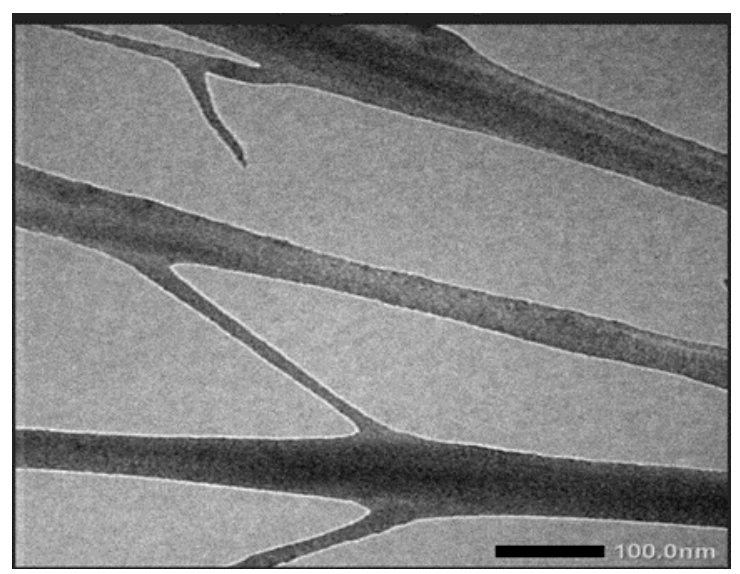

Figure.3.TEM image of cellulose nanofiber (CNF)

In the other hand, scanning electron microscope (SEM) was used to investigate microstructure of the CNF/GO nanocomposite films. Fig.4. shown SEM image of the surface morphology of RC 0.00 and RC 0.06 with magnification 1000x. It indicated that graphene oxide nanosheet weredispersed within the cellulose nanofiber matrix(Amaturrahim et al., 2018)(Zhang et al., 2012). The strong adhesion between cellulose nanofiber fibers and graphene oxide nanosheet was beneficial to improve the mechanical properties of $\mathrm{CNF} / \mathrm{GO}$ nanocomposites (Amaturrahim et al., 2018). 


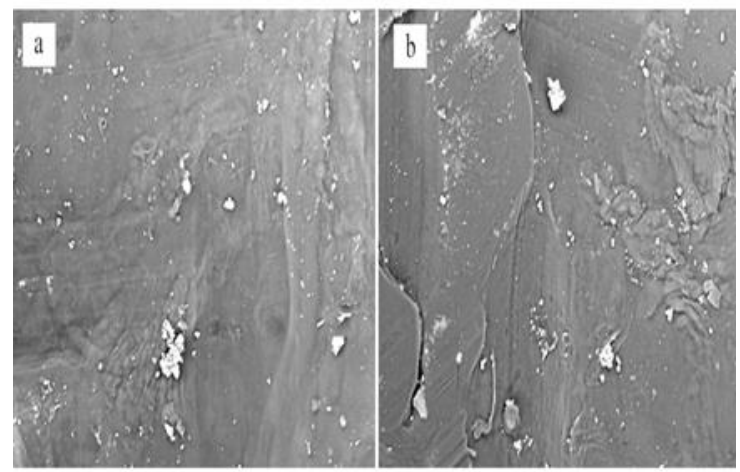

Figure. 4.SEM image of CNF/GO nanocomposite films (a) RC $0.00 \mathrm{GO}$ wt $\%$, (b) RC $0.06 \mathrm{GO}$ wt $\%$

\section{Conclusions}

In this work, cellulose nanofiber/graphene oxide (CNF/GO) nanocomposite was successfully prepared by mixing method. During mixing process, cellulose nanofiber has very strong interaction with graphene oxide and made graphene oxide well dispered into cellulose nanofiber matrix. The cellulose nanofiber/graphene oxide nanocomposite films exhibited a significant improvement on mechanical properties. With these enhancements, the cellulose nanofiber/graphene oxide nanocomposite films may find applications in the future.

Acknowledgement. The authors would like to acknowledge the Rector of University of Sumatera Utara, Medan, Indonesia, for the financial support via Penelitian Dasar Unggulan Universitas Talenta Project 2018 scheme.

\section{References}

[1]Alam, S. N., Sharma, N. and Kumar.: 'Synthesis of Graphene Oxide (GO) by Modified Hummers Method and Its Thermal Reduction to Obtain Reduced Graphene Oxide (rGO)*', Graphene. doi: 10.4236/graphene.2017.61001. (2017)

[2]Amaturrahim, S. A. et al.: Preparation of grapheneoxide/bacterial cellulose nanocomposite via in situ process in agitated culture', Asian Journal of Chemistry. doi: 10.14233/ajchem.2018.21244 (2018)

[3]Feng, Y. H. et al.: 'Characteristics and environmentally friendly extraction of cellulose nanofibrils from sugarcane bagasse', Industrial Crops and Products. Elsevier, 111(March 2017), pp. 285-291. doi: 10.1016/j.indcrop.2017.10.041 (2018)

[4]Ferrer, A. et al.: Valorization of residual Empty Palm Fruit Bunch Fibers (EPFBF) by microfluidization: Production of nanofibrillated cellulose and EPFBF nanopaper', Bioresource Technology. Elsevier Ltd, 125, pp. 249-255. doi: 10.1016/j.biortech.2012.08.108 (2012)

[5]Julie Chandra, C. S., George, N. and Narayanankutty, S. K.: 'Isolation and characterization of cellulose nanofibrils from arecanut husk fibre', Carbohydrate Polymers. Elsevier Ltd., 142, pp. 158166. doi: 10.1016/j.carbpol.2016.01.015. (2016) 
[6]Kalia, S. et al.: Cellulose-based bio- and nanocomposites: A review', International Journal of Polymer Science. doi: 10.1155/2011/837875 (2011)

[7]Kaushik, A. and Singh, M.: 'Isolation and characterization of cellulose nanofibrils from wheat straw using steam explosion coupled with high shear homogenization', Carbohydrate Research, 346(1), pp. 76-85. doi: 10.1016/j.carres.2010.10.020 (2011)

[8]Lee, S. Y. et al.: 'Preparation of cellulose nanofibrils by high-pressure homogenizer and cellulosebased composite films', Journal of Industrial and Engineering Chemistry, 15(1), pp. 50-55. doi: 10.1016/j.jiec.2008.07.008 (2009)

[9]Lu, G., Ocola, L. E. and Chen, J.: 'Reduced graphene oxide for room-temperature gas sensors', Nanotechnology, 20(44), p. 445502. doi: 10.1088/0957-4484/20/44/445502 (2009)

[10]Ohwoavworhua, F. and Adelakun, T.: Some Physical Characteristics of Microcrystalline Cellulose Obtained from Raw Cotton of Cochlospermum planchonii', Tropical Journal of Pharmaceutical Research. doi: 10.4314/tjpr.v4i2.14626. (2005)

[11]Or, K. H., Putra, A. and Selamat, M. Z.: Oil palm empty fruit bunch fibres as sustainable acoustic absorber', Applied Acoustics. Elsevier Ltd, 119, pp. 9-16. doi: 10.1016/j.apacoust.2016.12.002. (2017)

[12]Phiri, J. et al.: A comparative study of mechanical, thermal and electrical properties of graphene-, graphene oxide- and reduced graphene oxide-doped microfibrillated cellulose nanocomposites', Composites Part B: Engineering. Elsevier Ltd, 147, pp. 104-113. doi: 10.1016/j.compositesb.2018.04.018 (2018)

[13]Saelee, K. et al..: An environmentally friendly xylanase-assisted pretreatment for cellulose nanofibrils isolation from sugarcane bagasse by high-pressure homogenization', Industrial Crops and Products. Elsevier B.V., 82, pp. 149-160. doi: 10.1016/j.indcrop.2015.11.064. (2016)

[14]Salehudin, M. H. et al.: Starch based Active Packaging Film Reinforced with Empty Fruit Bunch (EFB) Cellulose Nanofiber', Procedia Chemistry. Elsevier Ltd., 9, pp. 23-33. doi: 10.1016/j.proche.2014.05.004. (2014)

[15]Sinaga, M. Z. E. et al.: The preparation of cellulose nanocomposite film from isolated cellulose of corncobs as food packaging,, Oriental Journal of Chemistry, 34(1), pp. 562-567. doi: $10.13005 / \mathrm{ojc} / 340166$ (2018)

[16]Sitko, R. et al.: Adsorption of divalent metal ions from aqueous solutions using graphene oxide', Dalton Transactions, 42(16), p. 5682. doi: 10.1039/c3dt33097d (2013)

[17]Song, J. et al.: Preparation and Characterization of Graphene Oxide', Journal of Nanomaterials, 2014, pp. 1-6. doi: 10.1155/2014/276143. (2014)

[18]Wang, F., Wu, Y. and Huang, Y.: 'Novel application of graphene oxide to improve hydrophilicity and mechanical strength of aramid nanofiber hybrid membrane', Composites Part A: Applied Science and Manufacturing. Elsevier, 110(April), pp. 126-132. doi: 10.1016/j.compositesa.2018.04.023. (2018)

[19]Zhang, X. et al.: 'Regenerated cellulose/graphene nanocomposite films prepared in DMAC/LiCl solution', Carbohydrate Polymers. Elsevier Ltd., 88(1), pp. 26-30. doi: 10.1016/j.carbpol.2011.11.054 (2012) 